\title{
ADDITIONAL CURRICULUM MODIFICATIONS FOR ENHANCING THE TEACHING OF PARASITOLOGY AND INFECTIOUS DISEASES AT AN ENGLISH UNIVERSITY
}

\author{
A. Peña-Fernández ${ }^{1}$, G. Torrado² ${ }^{2}$ R. Agudo ${ }^{3}$, M.A. Peña ${ }^{2}$ \\ ${ }^{1}$ De Montfort University, School of Allied Health Sciences, Faculty of Health and Life \\ Sciences (UNITED KINGDOM) \\ ${ }^{2}$ Universidad de Alcalá, Departamento de Ciencias Biomédicas (SPAIN) \\ ${ }^{3}$ Universidad San Pablo CEU, Facultad de Farmacia (SPAIN)
}

\begin{abstract}
Our teaching innovation group is committed to increasing and enhancing the teaching of parasitology, as recent surveys show an alarming decrease in the teaching of this subject in human health degrees despite recent outbreaks threatening public health in Europe that have involved emerging parasites. Since 2016/17, we have started to perform a series of curriculum modifications in the BSc Biomedical Science (BMS) programme at De Montfort University (DMU, UK), following the subject-specific threshold standards described by the Quality Assurance Agency (QAA, 2015) [1]. These modifications targeted specifically two modules from this Institute of Biomedical Sciences (IBMS) accredited programme: Basic Microbiology for Biomedical Science (level 4) and Medical Microbiology (level 6). We performed detailed analysis and evaluation of the impact of these preliminary changes on our students, which have been described in Peña-Fernández et al. (2017) [2]. Briefly, students highlighted high levels of engagement in both modules. The most notable improvement was detected in the Basic Microbiology module that showed an increase of $44 \%$ in the students' satisfaction from $20 \%$ in $2015 / 16$ to $64 \%$ in $2016 / 17$; and a reduction in the dissatisfaction from $20 \%$ to $7.4 \%$ in Medical Microbiology. We have performed further curriculum modifications following students' feedback and current pedagogic research undertaken by our international teaching innovation group. Thus, we have tackled and introduced new lectures in our Basic Microbiology level 4 module to describe better the differences between bacteria and the characteristics of parasites and viruses. A new lecture about human immunodeficiency virus (HIV) has been included following the detection of a lack of knowledge of preventative measures (HIV chemoprophylaxis including pre- and post-exposure prophylaxis and HIV screening) and transmission (risk behaviours) in a novel training session offered to second year BMedSci Medical Science students in 2016/17. Finally, we have introduced a new workshop session in which students completed a virtual clinical case study from the novel teaching and learning resource DMU e-Parasitology (these resources are publicly available at: http://parasitology.dmu.ac.uk/learn /case-studies.htm). Two workshops have been created and introduced in these two BMS modules and we have followed previous successful experiences creating and introducing novel research-led workshops in human health undergraduate degrees. Finally, we are also creating an on-line resource for the teaching and learning of HIV in collaboration with the University of San Pablo CEU (Spain), which will be accessible on the DMU website by the end of 2018. A more detailed description of the curriculum modifications implemented in this academic course 2017/18 are provided in this paper in conjunction with an analysis of students' impressions that will be collected in the final module level feedback for each module through the online resource Blackboard.
\end{abstract}

Keywords: Curriculum modifications, teaching parasitology, infectious diseases, undergraduate students, biomedical science.

\section{INTRODUCTION}

Medicine and related human health degrees in universities in developed countries are progressively delivering less parasitology content despite increasing cases of parasitic infections in these countries. To enhance the academic status of parasitology and infectious diseases we have performed two sets of curriculum modifications in the BSc Biomedical Science (BMS) programme at De Montfort University (DMU, UK) in 2016/17 and this academic course, 2017/18. Both sets of curriculum modifications were performed in two BMS modules: Basic Microbiology for Biomedical Science (level 4) and Medical Microbiology (level 6); and were undertaken following the subject-specific threshold 
standards described by the Quality Assurance Agency (QAA, 2015) [1] in collaboration with EU academics and first responders to the 2014-16 Ebola outbreak in West Africa.

\subsection{Preliminary outcomes observed in 2016/17}

A detailed analysis and evaluation of the impact of the preliminary changes undertaken in the first set (i.e. in 2016/17) were described in Peña-Fernández et al. (2017) [2]. Briefly, the interim and final module level feedback (MLF; a specific on-line questionnaire for each module that is distributed to all undergraduate students enrolled in the module at the appropriate time) in the targeted modules showed a general increment in the students' enjoyment and satisfaction in both modules, although this increment was more evident in the level 4 module Basic Microbiology, as the students' satisfaction increased from $20 \%$ in $2015 / 16$ to $64 \%$ in $2016 / 17$ [2]. The interim MLF was a trial and only performed on the $2016 / 17$ course.

\subsection{Further modifications undertaken in 2017/18}

A second set of curriculum modifications was implemented following the final MLF provided by $2016 / 17$ students and the pedagogic research that our international teaching innovation group is currently performing.

\subsubsection{Modifications performed in Basic Microbiology module}

Students enrolled in Basic Microbiology in 2016/17 demanded more support with foundation knowledge in parasitology and microbiology, as it was the first time that the majority of the cohort studied these scientific fields. To support this, students suggested the introduction of more tutorials and interactive sessions where they could enhance their learning. Thus, we have tackled former lectures and introduced new ones to better describe the differences between bacteria and the characteristics of parasites and viruses, modifications that are detailed in Table 1. Relevant changes included:

- The introduction of three new lectures to describe the different types of bacteria (highlighted in light green in Table 1) instead of the former topic "Bacterial cell structure" and a reduction to only one lecture of "Taxonomy of microbes" (indicated in violet in Table 1).

- The former four lectures that covered the microbial genetics part of the module have been updated to three single lectures to facilitate the assimilation of this topic to our students (highlighted in light yellow in Table 1).

Table 1. List of lectures of "Basic Microbiology for Biomedical Science" for 2016/17 and changes undertaken for this academic course, 2017/18.

\begin{tabular}{|c|c|}
\hline $2016 / 17$ & $2017 / 18$ \\
\hline Introduction to the module & Same \\
\hline \multirow[t]{3}{*}{$\begin{array}{l}\text { Bacterial cell structure; difference between prokaryote } \\
\text { and eukaryote; staining methods }\end{array}$} & $\begin{array}{l}\text { Prokaryote: archaea and bacteria. Types, nutrition } \\
\text { and reproduction }\end{array}$ \\
\hline & $\begin{array}{l}\text { Cell walls of archaea and bacteria. Microbial } \\
\text { locomotion. Staining methods }\end{array}$ \\
\hline & Differences between prokaryote and eukaryote \\
\hline Taxonomy of microbes (Parts I \& II) & Taxonomy of microbes \\
\hline Medically important Gram negative bacteria (Parts I \& II) & Same \\
\hline Spirochetes & Same but with less content \\
\hline $\begin{array}{l}\text { Medically important Gram positive bacteria-non-spore } \\
\text { forming }\end{array}$ & Same \\
\hline Medically Important Gram positive bacteria-spore forming & Same \\
\hline Microbial growth & Same \\
\hline Microbial interactions with humans - normal microflora & Same \\
\hline Microbial genetics - bacterial genetics (Parts I \& II) & Bacterial genetic structure \\
\hline
\end{tabular}




\begin{tabular}{|l|l|}
\hline Microbial genetics - genetic function (Parts I \& II) & Bacterial genetic functions \\
\cline { 2 - 2 } & Bacterial genetic transformation \\
\hline Microbial evolution & Same \\
\hline $\begin{array}{l}\text { Antimicrobials and antimicrobial drug resistance (Parts I } \\
\text { \& II) }\end{array}$ & Same \\
\hline Antibiotic susceptibility testing (Parts I \& II) & Same \\
\hline Infection detection methods and infection control & Same \\
\hline Sterilisation and disinfection & Content was introduced in "Infection control" \\
\hline Viruses (Parts I \& II) & Introduction to viruses \\
\cline { 2 - 2 } & Human Immunodeficiency Virus (HIV) \\
\hline Mycology (Parts I \& II) & Same but with less content \\
\hline Parasites (Parts I, II \& III) & Same but with less content \\
\hline Emerging Infectious Diseases & Same \\
\hline
\end{tabular}

- The previous two lectures on viruses where too complex for students so we have simplified it to one lecture that covers a brief introduction regarding human viruses and a new lecture delivered in a tutorial style about the human immunodeficiency virus (HIV) and how to prevent infections in a young population (indicated in light blue in Table 1). We considered that the introduction of this topic will partially address the lack of knowledge of preventative measures (HIV chemoprophylaxis including pre- and post-exposure prophylaxis and HIV screening) and transmission (risk behaviours) previously detected in second year BMedSci Medical Science students in 2016/17 during the delivery of a specialised workshop [3].

- The lecture "Sterilisation and disinfection" was removed by introducing this topic in other lectures such as "Infection detection methods and infection control" (shown in pink in Table 1). We also reduced the content of some lectures such as "Spirochetes" and the different lectures regarding mycology and parasitology.

\subsubsection{Modifications performed in Medical Microbiology module}

Students enrolled in this module in 2016/17 demanded that the content delivered be reduced and focused by reducing the number of external lecturers from the National Health Service and restricting in depth coverage to a few pathogens relevant for human health rather than a range of pathogens, to enhance their learning and comprehension. The module leader, Marilena loannou, performed these modifications. However, the most significant modification was the introduction of a clinical case study using the novel DMU e-Parasitology, which is explained below.

\subsubsection{Introduction of clinical case studies}

Finally, we created two interactive workshop sessions with different degrees of difficulty for both modules, i.e. easier for Basic Microbiology and more complex for Medical Microbiology. Both workshops followed the same teaching strategy, in which students completed one of the clinical case studies available at the DMU e-Parasitology's website here: http://parasitology.dmu.ac.uk/learn/casestudies.htm.

\section{METHODOLOGY}

For determining the effect of the modifications performed in 2017/18, two quantitative analyses were undertaken: i) analysis of the specific MLF survey in both modules and ii) the use of a specific feedback-questionnaire for determining the effectiveness of the novel workshops delivered. In this paper we will describe only the analysis of the MLF 2018 surveys due to time and space constraints.

\section{RESULTS AND DISCUSSION}

Students completed the final MLF 2018 survey from $16^{\text {th }}$ to $27^{\text {th }}$ of April 2018 for Basic Microbiology and Medical Microbiology. The numbers of students enrolled in each module and the percentages of participants that have appropriately completed the respective MLF can be found in Table 2 for the 
monitored academic years. A significant lack of engagement has been observed for current final year students (1.5\% of participation was recorded; Table 2 ), which could be attributed to poor timing of MLF release on 2017/18. The final MLF was released by the end of April by the university when all teaching for these modules was completed and students were preparing their final exams.

Table 2. Number of students enrolled in each module for each year with an indication of those that completed the respective MLF.

\begin{tabular}{|c|c|c|c|c|c|c|}
\cline { 2 - 7 } \multicolumn{1}{c|}{} & \multicolumn{2}{c|}{$2015 / 16$} & \multicolumn{2}{c|}{$2016 / 17$} & \multicolumn{2}{c|}{$2017 / 18$} \\
\cline { 2 - 7 } & Total & Responses & Total & Responses & Total & Responses \\
\hline $\begin{array}{c}\text { Basic } \\
\text { Microbiology }\end{array}$ & 227 & $30(13.2 \%)$ & 196 & $44(22.5 \%)$ & 187 & $27(14.4 \%)$ \\
\hline $\begin{array}{c}\text { Medical } \\
\text { Microbiology }\end{array}$ & 107 & $15(14.0 \%)$ & 120 & $22(18.3 \%)$ & 194 & $3(1.5 \%)$ \\
\hline
\end{tabular}

\subsection{Basic microbiology}

The first set of curriculum modifications performed in this module resulted in a significant increment in student satisfaction in Basic Microbiology module in 2016/17, but this trend has not been enhanced by the implementation of the second set of curriculum modifications explained in this paper, as it can be seen in Figure 1. Thus, similar levels of satisfaction are reported when comparing 2018 vs. 2017 (62.9\% vs. $63.9 \%$; these percentages show the sum of 'agreed' and 'strongly agreed' responses).

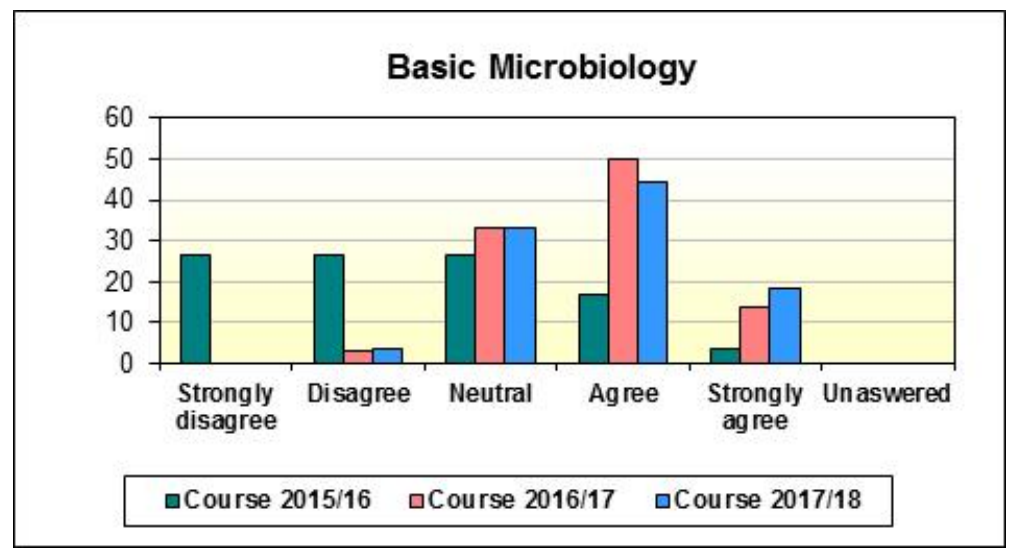

Figure 1. Student satisfaction (\%) for Basic Microbiology per academic year. Absence of a Likert category indicates no responses for that category

However, some slight improvements have been highlighted by participants in the MLF 2018. Thus, students have indicated that the module was well organised $(48.1 \%$ agreed, $22.2 \%$ strongly agreed $)$ although a small percentage of students disagreed $(7.4 \%)$ possibly because of the discrepancies in the amount of content delivered by the different lecturers involved in this module, which also resulted in differences in the amount of content delivered in the lectures.

Surprisingly, some participants indicated again the necessity of enhancing the support in the foundation knowledge of microbiology and parasitology delivered in this module despite the significant changes implemented in the syllabus (Table 1). To try to resolve this and to facilitate transition from school/college to university, we will create a series of e-learning units on the foundations of these scientific disciplines that will be covered between the DMU e-Parasitology [4] and the future DMU eBiology [5] websites.

In relation with the aims of these curriculum modifications, only $3.7 \%$ of students indicated that they did not gain some knowledge about malaria and other major parasitic diseases through the combination of specific lectures and the workshop (33.3\% strongly agreed; $48.1 \%$ agreed; $14.8 \%$ neither agreed nor disagree).

Finally, students were specifically asked if the new session on HIV would require any improvement. Participants indicated that they generally enjoyed this session and did not suggest any specific action. 


\subsection{Medical microbiology}

A slight improvement was observed in students' satisfaction from $59.3 \%$ to $66.7 \%$ from $2016 / 17$ to this current academic course (if we consider percentage responses for 'agree' and 'strongly agree' together; Fig. 2). However, these results are inconclusive due to the very low number of participants that completed the final MLF in $2018(n=3$; Table 1).

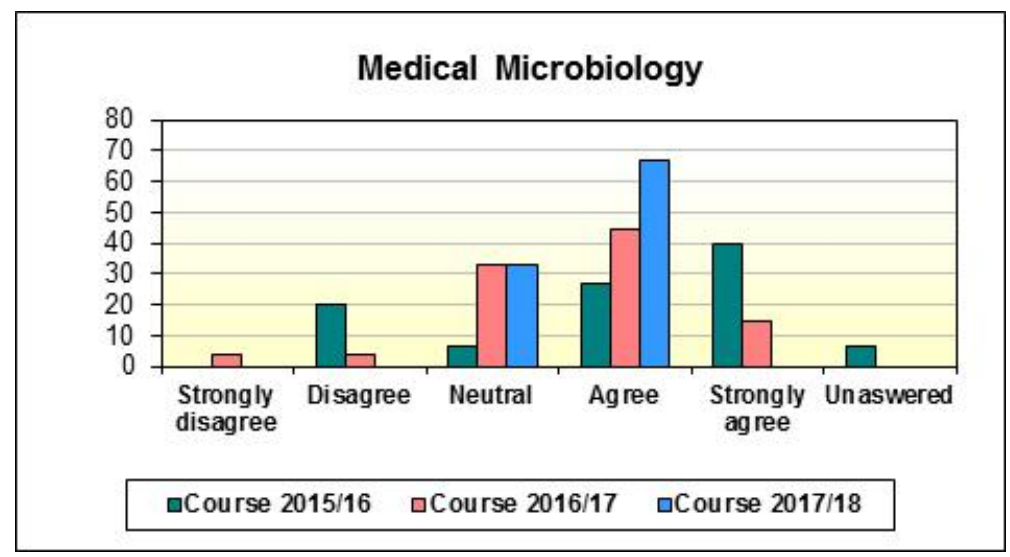

Figure 2. Student satisfaction (\%) for Medical Microbiology per academic year. Absence of a Likert category indicates no responses for that category.

Additionally, $66.7 \%$ (agreed) of participants indicated that they gained a better understanding of medical microbiology (33.3\% neither agreed nor disagreed). However, more studies will be needed to determine whether this would be a real outcome derived from the curriculum modifications performed due to the low number of participants that completed the MLF 2018.

\subsection{DMU e-Parasitology workshops}

The creation and structure of the first virtual clinical case study related to human pathogenic amoebae, which was used to develop the more complex workshop, is described in a separate paper submitted to the EDULEARN2018 proceedings [6]. In that paper we also explore the effectiveness of the highly specialised workshop created with a focus group of postgraduate students attending the MSc. Advanced Biomedical Science programme at DMU; the workshop delivered to MSc. students was simplified to be used in Medical Microbiology module.

After appropriate adaptation, we have also created and delivered a more basic workshop involving the second virtual clinical case study created so far, which involves a malaria clinical case. Both workshops have been delivered in these two modules in 2017/18 and we have collected comprehensive feedback and data from those students that will be reported in a future paper. However, Basic Microbiology students have indicated in the MLF that they enjoyed the DMU eParasitology workshop (22.2\% strongly agreed; $40.7 \%$ agreed; $33.3 \%$ neither agreed nor disagree), as well as Medical Microbiology (66.7\% agreed; $33.3 \%$ neither agreed nor disagreed) although these results should be treated cautiously until the specific feedback-questionnaires distributed to analyse the academic effect of the novel workshops have been studied.

\section{CONCLUSIONS}

Our results indicate that the two sets of curriculum modifications performed in the microbiology-related modules taught in the BSc. Biomedical Science programme could have resulted in a general improvement in students' satisfaction and could facilitate the acquisition of knowledge of parasitology and infectious diseases. The methods and teaching resources described in this paper could be used to improve the current academic status of medical parasitology in human health degrees.

\section{ACKNOWLEDGEMENTS}

The authors would like to express their sincere appreciation to Jonathan Coope and Maxine Armstrong (DMU) for work on development of DMU e-Parasitology. Moreover, we would like to thank 
the Teaching Innovation Project Fund at De Montfort University (scheme 2015-16) awarded to Dr. Peña-Fernández for funding this project to.

\section{REFERENCES}

[1] QAA. Subject Benchmark Statement: Biomedical Sciences, 2015. Available at: http://www.qaa.ac.uk/publications/information-andguidance/publication?PubID=3013\#.Wbf4Xk2Wxfw [accessed 10/05/2018]

[2] Peña-Fernández A., Ioannou M., Lobo-Bedmar MC., Fenoy S. Curriculum modifications for teaching parasitology and infectious diseases in a Biomedical Science degree. ICERI2017 Proceedings; 1593-1598. ISBN: 978-84-697-6957-7.

[3] Peña-Fernández A., Peña MA., Evans MD. Introducing training related to the use of drugs to protect humans from HIV infection. ICERI2017 Proceedings; 7123-7127. ISBN: 978-84-6976957-7.

[4] Peña-Fernández A., Magnet A., Acosta L., Evans MD., Fenoy MS. Developing a digital environment for teaching and learning parasitology. Higher Education Academy STEM conference 2018, Newcastle, UK, 31st Jan - 1st Feb 2018. Oral presentation. Available at: https://www.heacademy.ac.uk/knowledge-hub/developing-digital-environment-teaching-andlearning-parasitology-stem-conference

[5] Peña-Fernández A., Sgamma T., Young C., Randles MJ., Del Águila C., Hurtado C., Evans MD., Potiwat N., Izquierdo F., Peña MA., Coope J., Armstrong M., Bhambra A. Building a DMU e-Biology resource for health sciences' students. ICERI2017 Proceedings; 1582-1587.

[6] Peña-Fernández A., Magnet A., Peña MA. Focus group to create a virtual case study model unit for the DMU e-Parasitology. EduLearn2018 Proceedings; submitted for publication. 